\title{
Recycling of DLC-Coated Tools for Dry Machining of Aluminum Alloys via Oxygen Plasma Ashing
}

\author{
Tatsuhiko Aizawa ${ }^{1}$, Eijirou Masaki ${ }^{1}$, Eiji Morimoto $^{2} \&$ Yoshio Sugita $^{3}$ \\ ${ }^{1}$ Department of Engineering and Design, Shibaura Institute of Technology, Tokyo, Japan \\ ${ }^{2}$ Green Tool Co. Ltd., Okayama, Japan \\ ${ }^{3}$ YS-Electric Industry, Co. Ltd., Kofu, Japan \\ Correspondence: Tatsuhiko Aizawa, Department of Engineering and Design, Shibaura Institute of Technology, \\ Tokyo 108-8548, 3-9-14 Shibaura, Japan. Tel: 81-3-6722-2741. E-mail: taizawa@sic.shibaura-it.ac.jp
}

$\begin{array}{lc}\text { Received: January 12, } 2014 & \text { Accepted: February 8, } 2014 \quad \text { Online Published: March 20, } 2014 \\ \text { doi:10.5539/mer.v4n1p52 } & \text { URL: http://dx.doi.org/10.5539/mer.v4n1p52 }\end{array}$

\begin{abstract}
DLC coated tools have been widely utilized in the dry milling and cutting of aluminum alloy parts and components for automotive industries and cellular phone makers. Most of these tools are inevitably exchanged with new ones to preserve high quality of machined products. Then, the used DLC coating must be removed or ashed away before grinding and polishing. Complete removal of used DLC coating plays a key to make DLC-recoating onto the ashed surface of tools for their reuse. High density oxygen plasma ashing provides a solution to make perfect ashing of DLC coating together with metallic interlayers before recoating. In the present paper, this plasma system with quantitative diagnosis instrumentation is first stated to describe the effect of processing conditions on the ashing behavior. Two types of end-milling tools were prepared to prove that the whole DLC-coating should be completely removed with fast rate. This ashed tool substrate was ground and DLC-recoated to demonstrate that the reused tools have the same machinability in dry as the original virgin tools through dry milling experiments.
\end{abstract}

Keywords: DLC-coated tools, oxygen plasma ashing, perfect removal of DLC coating, recoating, dry machinability tests, aluminum alloys, surface quality

\section{Introduction}

The aluminum alloys have been widely utilized as a light-weight structural material with higher specific strength in the aircraft components and automotive parts for further reduction of $\mathrm{CO}_{2}$ emission in transportation (Cole, 1997). In recent years, mobile phone cover cases are fabricated by directly machining the aluminum alloys with high cost competitiveness (Samsung, 2013). In the above mass-productive machining, tool life extension becomes the first necessary condition to shorten the leading time with low production cost and to save materials and resource. Environmentally friendly machining under MQL (minimum quantity lubrication) as well as dry machining becomes the second necessary condition to be responsible for environmentally benign manufacturing. In particular, little or no need for post-cleansing of dry- or semi-dry machined aluminum alloy parts is attractive to industries (Gangopadhyay, Acharya, Chattopadhyay, \& Sargade, 2010).

DLC (Diamond-Like Carbon) coating is high-lighted as a promising method to prolong the tool life in practice. As had been reported in Jones (2012) and Zolgharni, Jones, Bulpett, Anson, and Franks (2008), adhesion of aluminum alloys to cutting tools was significantly reduced by DLC coating. In case of bare tools, the wrought aluminum alloy was easy to glue into teeth of tools even at the beginning stage of machining. On the other hand, DLC-coated cutting tools were free from adhesion of work materials. However, the DLC film thickness was inevitably reduced by abrasive wear during dry milling or cutting. This suggests that the used DLC coating should be removed once for recoating the original tool substrates to reuse them. This recycling of tool substrate materials is indispensable to save the tool materials cost such as $\mathrm{WC}(\mathrm{Co})$ or super-alloys but also to preserve the product surface quality with proof of originally tailored tool surfaces.

The authors (Aizawa, 2011; Aizawa \& Sugita, 2011; Aizawa \& Fukuda, 2012, 2013; Aizawa, Mizushima, Redationo, \& Yang, 2013) have developed the high density oxygen plasma ashing process to make fast-rate removal of DLC coating on the molds and dies without deterioration of their surface quality. In fact, this 
approach was successfully applied to reuse of WC (Co) die for mold-stamping the oxide-glass lens by ashing the used DLC coating and by recoating DLC onto the recycled die. At the presence of DLC coating in mold-stamping, adhesion of oxide glass melts onto the mold-die surface was much reduced even in the mold-stamping at $943 \mathrm{~K}$ in the inert gas atmosphere. In every 300 to 400 shots in stamping, the used DLC coating was ashed away for recoating. This recycling process resulted in much reduction of production cost with preservation of the original surface quality of mold-die. That is, complete ashing method of DLC coating established the recycling process of mold-die material without quality loss of mold surfaces. Furthermore, the authors (Aizawa \& Fukuda, 2013; Aizawa, Masaki, \& Sugita, 2014) discussed the possibility on the complete ashing of DLC coating from cutting tool surfaces.

The present paper is concerning with the suitable design of oxygen plasma ashing process for complete removal of used DLC coating from the end-milling tools with complex shaped teeth on them. First, the high density plasma ashing system is introduced to explain how to remove the DLC coating via the quantitative plasma diagnosis. High electron and ion density state is preferable to the fast rate ashing. In second, the DLC-coated end-milling tools are prepared as a specimen to demonstrate that DLC-coating on the tooth surfaces could be ashed away to leave the original tool material surfaces without its deterioration. In third, the ashed end-milling tools are DLC-recoated to make dry machinability testing. Direct comparison of recoated tool surfaces after dry machining reveals that the DLC-recoated tools are proven to have the equivalent quality in dry machinability to the virgin DLC coated tools.

\section{Experimental Procedure}

\subsection{High Density Oxygen Plasma Ashing System}

High density oxygen plasma ashing system was illustrated in Figure 1. In the conventional DC- or RF-plasma generators, the plasmas are ignited and generated in the frequency of $13.56 \mathrm{MHz}$ or its multiples. This high density oxygen plasma ashing system has no mechanical matching box. Input and out powers are automatically matched by frequency adjustment around $2 \mathrm{MHz}$. This difference in power matching reflects on the response time to temporally varying plasma states. The conventional mechanical matching requires for long response time in the order of $1 \mathrm{~s}$ to $10 \mathrm{~s}$ to adjust the RF-power. While, in the present system, it is shortened down to less than 1 $\mathrm{ms}$. There is no time delay in power control to drive the ashing process. In addition, the vacuum chamber is electrically neutral. Hence, RF-voltage and DC-bias are controlled independently from each other. RF-voltage was controllable up to $250 \mathrm{~V}$, while DC bias, $0 \mathrm{~V}$ to $-600 \mathrm{~V}$. A dipole electrode is utilized to generate RF-plasma, and, DC bias is directly applied to the specimens.
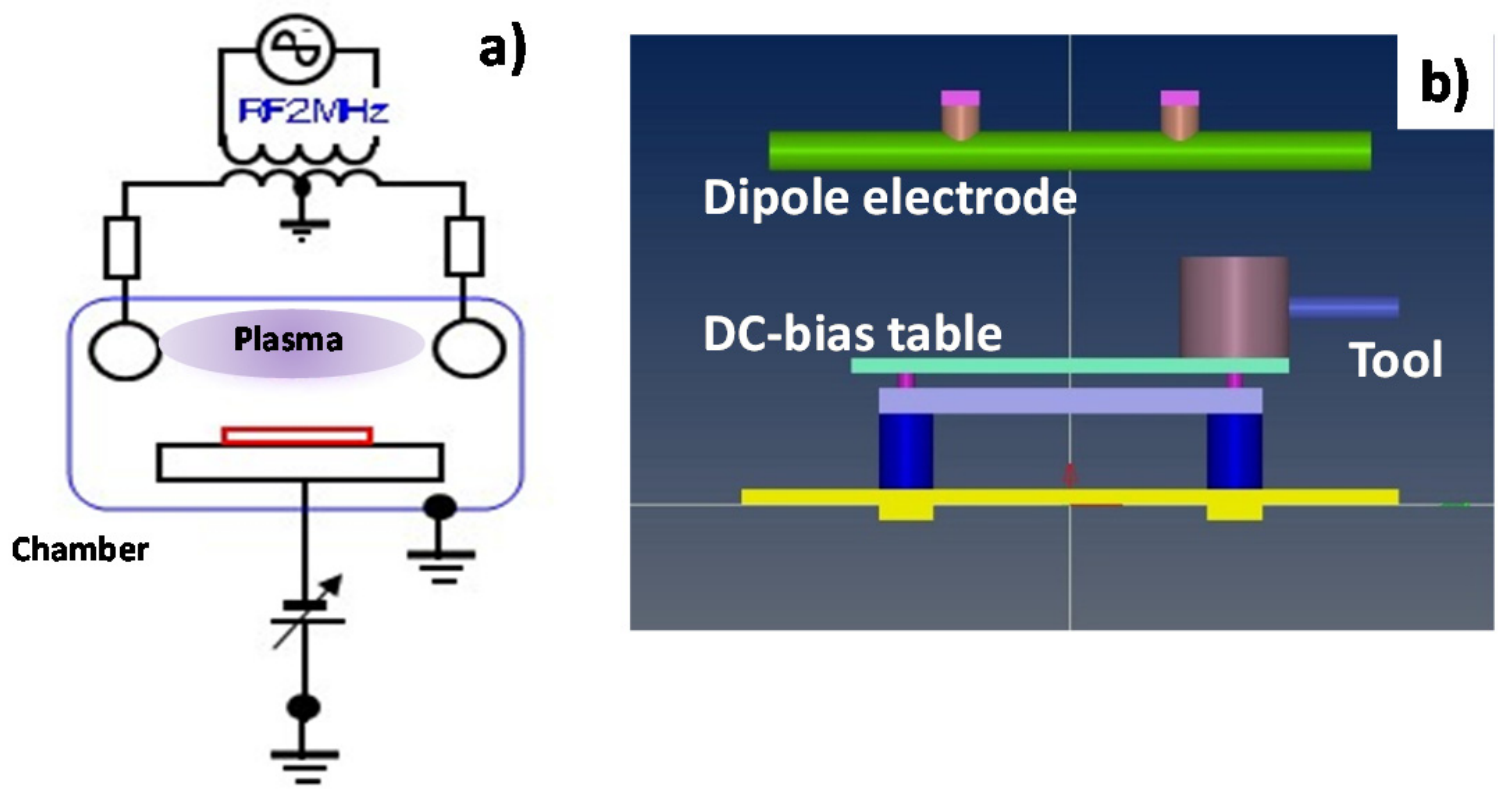

Figure 1. High density RF-DC oxygen ashing system. a) Illustration on the ignition of plasmas, and, b) Location of specimen holder on the cathode table 
Spectroscopic analyzer of emissive light from plasmas is instrumented in this system. The detector of emissive light is placed onto a silica window of chamber to transfer this light to the analyzer via the optical fibers. In addition, this spectroscopic analysis is performed to make on-line monitoring of plasmas. Through this analysis, each activated species in the plasmas is identified by its corresponding peak at the specified wave length. The Langmuir probe is also equipped to the present ashing system. Both the electron density and temperature are also on-line monitored during this ashing process. Both the density and temperature for electrons, ions and radicals are important parameters to define the plasma state for ashing process and to describe the effect of plasma processing parameters on the ashing behavior.

In the following ashing experiments, the specimens were located on the cathode table before evacuation down to the base pressure of $0.1 \mathrm{~Pa}$. Then, a carrier gas was introduced into the chamber to attain the specified pressure. Both oxygen and argon gases were available in this system besides the nitrogen gas for bent. With use of magnetic lens, the ignited RF-DC oxygen plasmas were focused onto the surface of specimens during ashing. Table 1 lists the standard processing conditions for ashing of DLC coating.

Table 1. Standard processing conditions for ashing of DLC coating

\begin{tabular}{cc}
\hline Processing Item & Parameters \\
\hline RF-Voltage & $250 \mathrm{~V}$ \\
DC-Bias & $-600 \mathrm{~V}$ \\
Carrier Gas & $\mathrm{O}_{2}$ Only \\
Partial Pressure & $15 \mathrm{~Pa}$ \\
Mass flow rate & $65 \mathrm{ml} / \mathrm{min}$ \\
Ashing duration time & $7.2 \mathrm{ks}$ \\
\hline
\end{tabular}

\subsection{Specimens}

Two types of specimen were prepared for ashing experiments. DLC-coated WC (Co) plate specimen, as shown in Figure 2a), is employed to describe the ashing behavior and to measure the removal rate of DLC coating. No metallic interlayers are present between the main DLC-film and the WC $(\mathrm{Co})$ substrate. Two end-milling tools are employed as a specimen to demonstrate the perfect removal of DLC coatings in practice. One specimen for long distance cutting test is a DLC-coated end-milling tool. It has three teeth with the skew angle of $45^{\circ}$, its diameter, $10 \mathrm{~mm}$, and, its total length, $100.15 \mathrm{~mm}$ as depicted in Figure $2 \mathrm{~b}$ ). The other for large volume milling test also has three teeth. Its diameter is $10 \mathrm{~mm}$, and, its total length, $100 \mathrm{~mm}$ as shown in Figure 2c). Each tooth has a skew angle of $45^{\circ}$ and a length of $15 \mathrm{~mm}$. The thickness of DLC film is constant at $3.0 \mu \mathrm{m}$ for both end-milling tools. DLC coating was performed by the ion-plating system in the Japan Coating Center, Co. Ltd. (JCC, 2014).

\subsection{Observation and Analysis}

Laser microscopy was employed to measure the thickness of masked DLC coating. Optical microscope and SEM (Scanning Electron Microscope) were utilized for surface observation of DLC-coated specimens before and after ashing. Raman spectroscopy was also used to detect the residual DLC fragments on the ashed tools. EDX (Electron Diffraction X-ray) was utilized to detect the chemical component distribution at the specified area of tool surface after ashing process.

\subsection{Dry End-Milling Test}

A machining center, DMU50 (Deckel Maho, Co. Ltd.) with the spindle of BT 40 was commonly employed for the following two dry end-milling tests. Table 2 summarizes the dry milling conditions for the long distance cutting test up to $200 \mathrm{~m}$ with use of DLC-recoated end-milling tools as shown in Figure 2b). As listed in Table 3, both the feed per tooth and the depth of cut are forwarded in case of the large volume milling up to $240 \mathrm{~cm}^{3}$ with use of DLC-recoated tools as depicted in Figure 2c). Type A5052 aluminum alloy is used as a work material. 

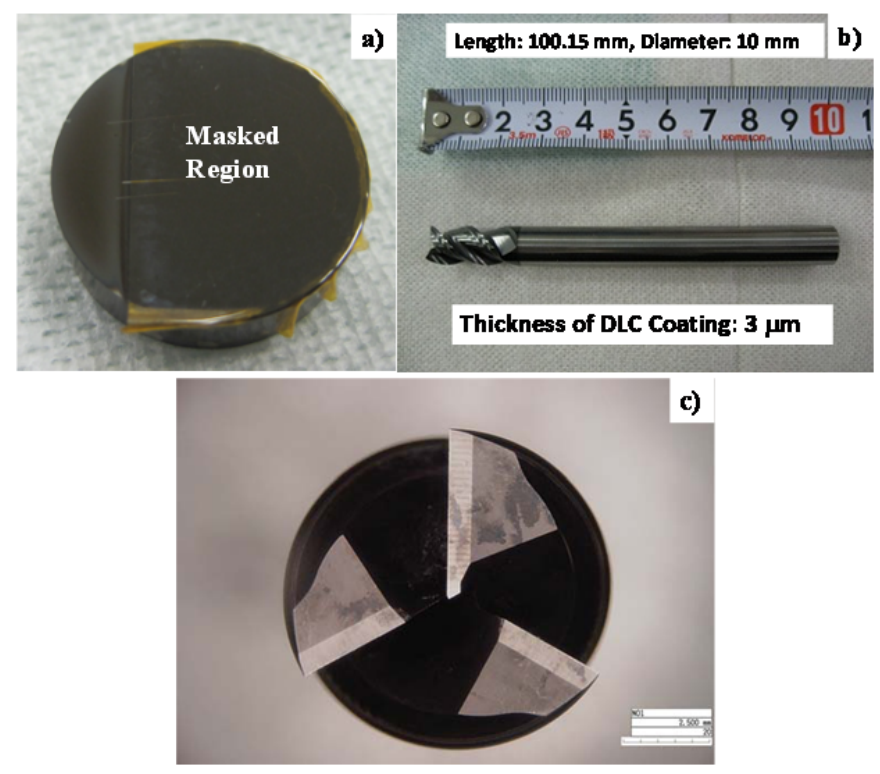

Figure 2. DLC-coated WC (Co) specimens. a) Plate specimen, b) End-milling tool specimen for long distance cutting, and c) End-milling tool for large volume machining

Table 2. Dry end-milling test condition for cutting in the distance of $200 \mathrm{~m}$

\begin{tabular}{cc}
\hline Processing Items & Parameters \\
\hline Spindle speed & $6350 \mathrm{~min}^{-1}$ \\
Cutting speed & $200 \mathrm{~m} / \mathrm{min}$ \\
Feed rate & $2250 \mathrm{~mm} / \mathrm{min}$ \\
Feed per tooth & $0.12 \mathrm{~mm} /$ tooth \\
Axial depth of cut & $10 \mathrm{~mm}$ \\
Radial depth of cut & $1 \mathrm{~mm}$ \\
Overhang & $30 \mathrm{~mm}$ \\
Cutting direction & Down-cutting \\
Actual cutting speed & $200 \mathrm{~m} / \mathrm{min}$ \\
\hline
\end{tabular}

Table 3. Dry end-milling test condition for cutting up to the removed volume of $240 \mathrm{~cm}^{3}$

\begin{tabular}{cc}
\hline Processing Items & Parameters \\
\hline Spindle speed & $6350 \mathrm{~min}^{-1}$ \\
Cutting speed & $200 \mathrm{~m} / \mathrm{min}$ \\
Feed rate & $2250 \mathrm{~mm} / \mathrm{min}$ \\
Feed per tooth & $0.15 \mathrm{~mm} / \mathrm{tooth}$ \\
Axial depth of cut & $12 \mathrm{~mm}$ \\
Radial depth of cut & $5 \mathrm{~mm}$ \\
Perpendicular depth of cut & $5 \mathrm{~mm}$ \\
Overhang & $30 \mathrm{~mm}$ \\
Cutting direction & Down-cutting \\
Actual cutting speed & $200 \mathrm{~m} / \mathrm{min}$ \\
\hline
\end{tabular}




\section{Experimental Results}

\subsection{Plasma Assisted Oxidation of DLC Coating}

With aid of quantitative plasma diagnosis in Saloum, Naddaf, and Alkhaled (2010) and Suenaga, Yunata, and Aizawa (2013), the activated plasma state is described to understand the reactivity between the oxygen plasmas and the DLC coating. Through the spectroscopic analysis of emissive light from oxygen plasmas, the state of activated species is analyzed to optimize the plasma processing parameters. The activated oxygen species are classified into $\mathrm{O}_{2}^{+}, \mathrm{O}^{*}$ and $\mathrm{O}$ (j) for $\mathrm{j}=\mathrm{II}$, III, and IV $\left(\right.$ or $\mathrm{O}^{+}, \mathrm{O}^{2+}$, and $\mathrm{O}^{3+}$ ). These population distributions are strongly dependent on the RF/DC conditions and plasma pressure. Activation into oxygen ions and radicals is accompanied with increase of electron density. Figure 3a) shows a typical emissive light spectrum of the fully developed plasma state. Besides a single, significant peak of $\mathrm{O}_{2}^{+}$, almost all the peaks come from the activated oxygen atoms and ions. This is because of cascading electron attachment and detachment reactions in series where $\mathrm{O}_{2}^{+}+\mathrm{e} \rightarrow 2 \mathrm{O}^{*}, \mathrm{O}^{*} \rightarrow \mathrm{O}^{+}+\mathrm{e}, \mathrm{O}^{+} \rightarrow \mathrm{O}^{2+}+\mathrm{e}$, and, $\mathrm{O}^{2+} \rightarrow \mathrm{O}^{3+}+\mathrm{e}$. Hence, huge amount of electrons is expected to be present with these activated species of $\mathrm{O}^{*}$ and $\left\{\mathrm{O}^{+}, \mathrm{O}^{2+}, \mathrm{O}^{3+}\right\}$. The Langmuir probe method is employed to measure the electron density and temperature in the present plasma state with comparison to the reference data for ICP (Inductively Coupled Plasma) in Cvelbar, Krstulovi, Miloševi, and Mozeti (2007). Table 4 assures that higher electron density is attained by the present method than ICP, intensified plasma state in the narrowed region. This higher population of $\mathrm{O}^{*}$ and $\mathrm{O}^{+}$is mainly responsible for reaction of oxygen atoms and ions with the carbon in DLC.

Figure $3 b$ ) depicts the emissive light spectrum from reactive oxygen plasma during ashing through narrow scanning in the spectroscopy. Significant peaks corresponding to CO (Aizawa et al., 2013a; Aizawa \& Fukuda, 2013; Cuesta, Mart'nez-Alonso, \& Tasco'n, 2001) are detected together with activated oxygen atom and ion peaks. This proves that DLC coating is ashed away by the chemical reaction of C (in DLC) $+\mathrm{O}$ (in plasmas) $\rightarrow$ $\mathrm{CO}$.
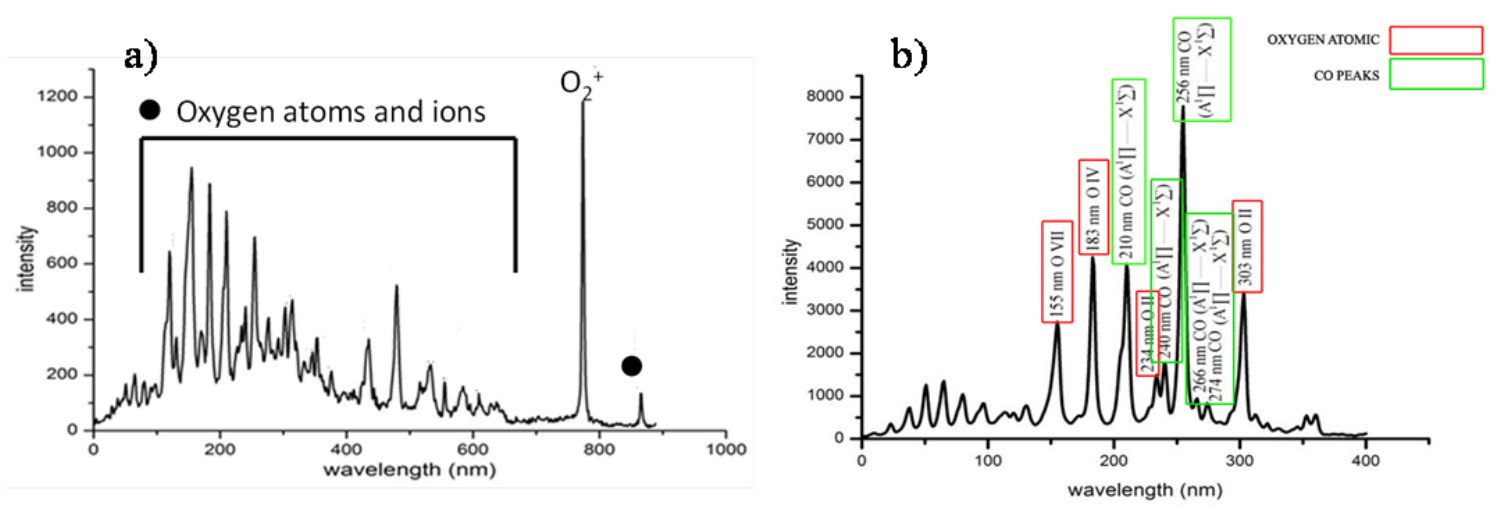

Figure 3. Spectrum of activated oxygen atoms, ions and resultants in the plasmas. a) measured spectrum of activated oxygen species in the plasmas, and b) detection of resultant, $\mathrm{CO}$, from direct reaction of carbon in DLC with oxygen atoms in plasmas

Table 4. Comparison of oxygen plasma parameters between the present plasmas and ICP

\begin{tabular}{ccc}
\hline $\begin{array}{c}\text { Process } \\
\text { Parameters }\end{array}$ & $\begin{array}{c}\text { Inductively Coupled } \\
\text { Plasma (Cvelbar, 2007) }\end{array}$ & Present Plasma \\
\hline Pressure & $75 \mathrm{~Pa}$ & $75 \mathrm{~Pa}$ \\
Plasma Configuration & $27.12 \mathrm{MHz}$ & $2 \mathrm{MHz}$ \\
& $300 \mathrm{~W}$ & $<300 \mathrm{~W}$ \\
Diameter of Chamber & $40 \mathrm{~mm}$ & $800 \mathrm{~mm}$ \\
Length of Chamber & $600 \mathrm{~mm}$ & $1,000 \mathrm{~mm}$ \\
Electron Density & $1 \times 10^{16} \mathrm{~m}^{-3}$ & $4.8 \times 10^{16} \mathrm{~m}^{-3}$ \\
Electron Temperature & $5 \mathrm{eV}$ & $3.9 \mathrm{eV}$ \\
\hline
\end{tabular}




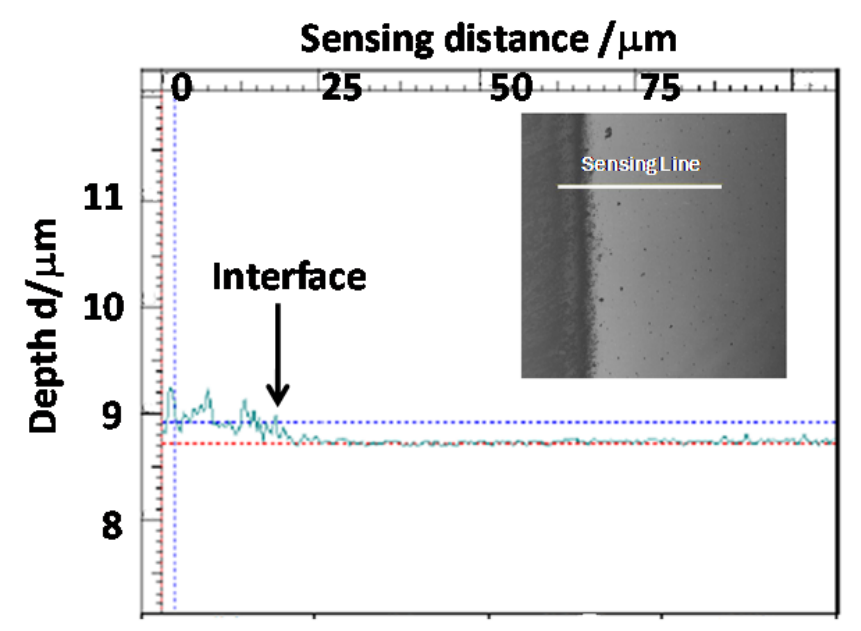

Figure 4. Depth profile of ashed DLC coating on the WC (Co) plate specimen with use of masking, analyzed by the laser-microscopy

\subsection{Ashing Performance of DLC-Coated WC (Co) Plates}

DLC-coated WC (Co) plate specimens are utilized to describe the plasma ashing behavior and to measure the ashing rate of DLC coating without any interlayers between the WC (Co) substrate and DLC coating. A half of DLC film is masked by polyimide tape. Figure 4 depicts the depth profile of ashed DLC coating on the WC (Co) plate specimen after $100 \mathrm{~s}$. Across the boundary of masking, the film thickness abruptly reduces from the original thickness of $200 \mathrm{~nm}$ to zero. Since no residual DLC films are left on the unmasked half of specimen, the original black colored surface of DLC film changes to be in metallic shining. The measured ashing rate is $2 \mathrm{~nm} / \mathrm{s}$ or $7.2 \mu \mathrm{m} / \mathrm{H}$.

\subsection{Ashing Performance of DLC-Coated WC (Co) End-Milling Tools}

The DLC-coated end-milling tool specimen, as shown in Figure $2 b$ ), is employed in the ashing experiment to prove that DLC coating is completely ashed away by the present process. Figure 5a) depicts the ashed specimen after two hours or $7.2 \mathrm{ks}$ with use of plasma ashing conditions in Table 1. Black-colored tool surface comes back to an original metallic shining. SEM image around the tooth is also shown in Figure 5b). No residuals of DLC film are seen even at the vicinity of tooth. The machined traces by grinding before DLC coating are only seen on the skewed surface of tooth.

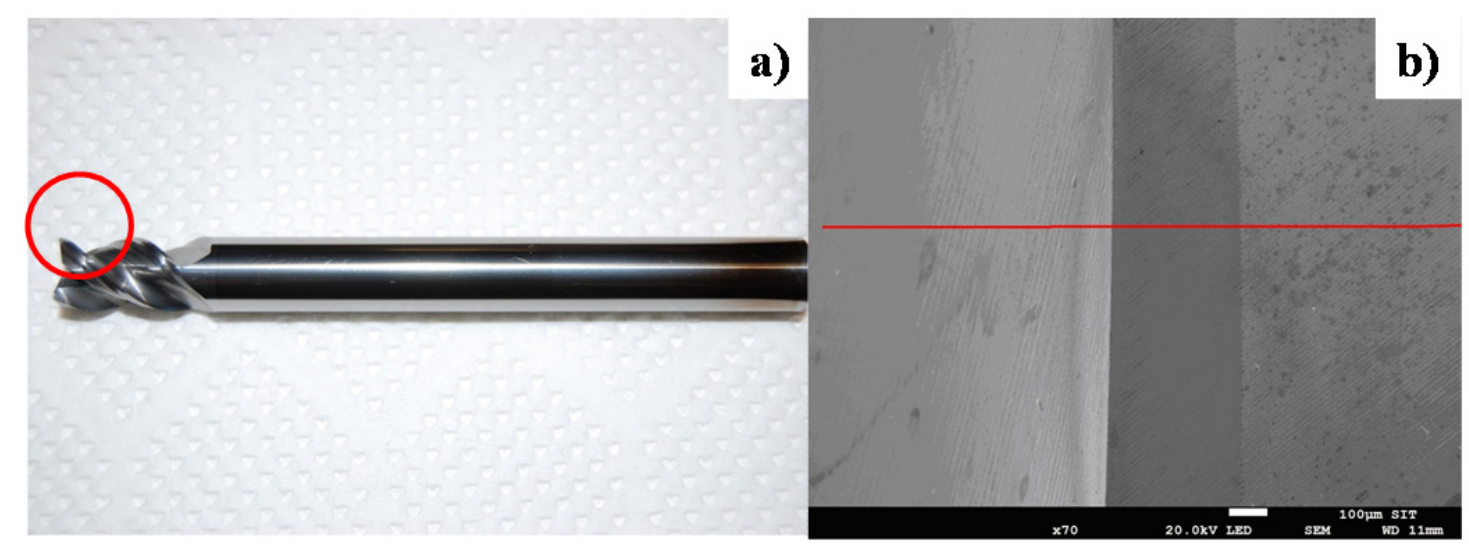

Figure 5. Observation of DLC-coated WC (Co) end-milling tool after ashing. a) Outlook of ashed WC (Co) tool, and b) SEM image of ashed WC (Co) tool at the vicinity of the first tooth

In general, the amorphous carbon film is characterized by the Raman spectroscopy to have a pair of two broad peaks around $1320 \mathrm{~cm}^{-1}$ and $1600 \mathrm{~cm}^{-1}$ respectively in the measured spectrum. Local tetragonal carbon structure 
or sp3 bonding state corresponds to the former D-peak; while the local planar structure or sp2 bonding state, to the latter G-peak. In addition, the area intensity ratio, or, $\mathrm{I}(\mathrm{D}) / \mathrm{I}(\mathrm{G})$ of these sp3- and sp2-peaks has correlation with hardness. That is, hardness is expected to be higher with increasing this $I(D) / I(G)$ ratio. Figure 6 a) depicts the Raman spectrum of original DLC coating before ashing. Higher area intensity ratio of two D and G-peaks proves that this DLC coating has high hardness enough to a protective coating for cutting tools. With reduction of film thickness, these peak intensities also reduce themselves; the similar spectra might be detected even for very thin DLC coating.

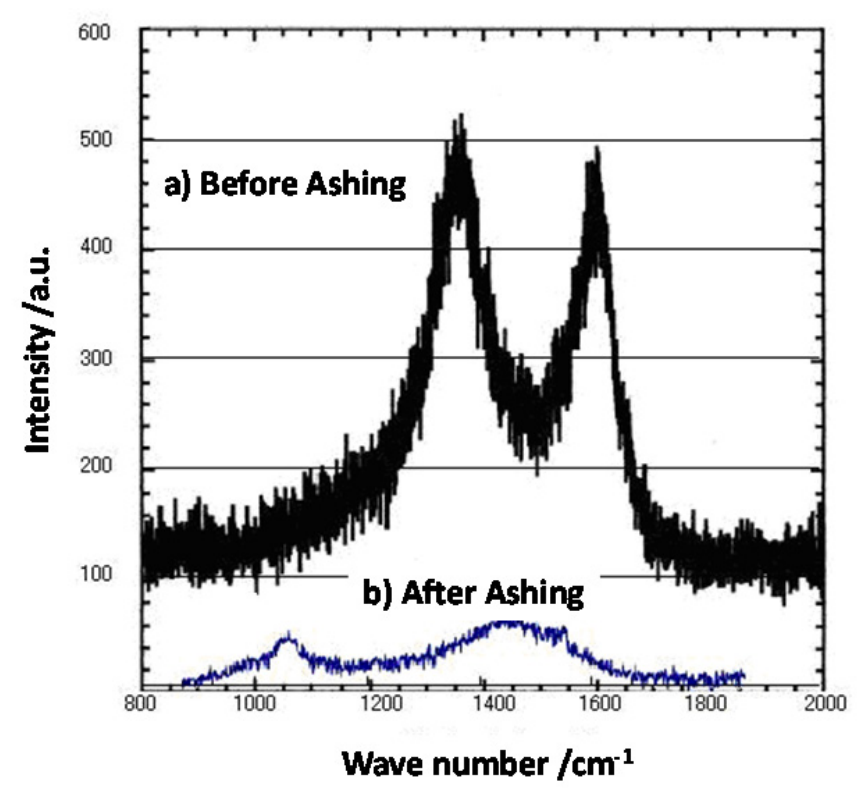

Figure 6. Comparison of Raman spectra for DLC-coated WC (Co) end-milling tool before and after ashing. a) Before ashing, and b) After ashing

Figure 6b) shows the measured Raman spectrum after ashing. No peaks are detected at the above specified wave numbers. Much broader spectra with weak peak intensities are only seen in this Figure 6b). This detection reveals that residuals on the tool surface could be only dirt or surfactant if they were. That is, the whole DLC coating layer is ashed away by this process for $7.2 \mathrm{ks}$.

Different from the plate specimen in Figure 2a), the chromium undercoat was deposited as a metallic interlayer on the tool surface before DLC coating. Aiming at reliable DLC-recoating, this metallic interlayer must be also removed together with DLC coating. Then, once the chromium could be detected on the ashed surface, the metallic interlayer must be left as a residual. Figure 7 depicts the chemical component distribution along the scanning line in Figure 5b). Since the tool material is WC (Co), both the tungsten and cobalt are detected by EDX analysis. In particular, the average content of Co was 10 at \%; this is just corresponding to the original cobalt content of WC (Co). In comparison to these data, little chromium is detected in Figure 5b). Its average of line-detected content is only 0.3 at $\%$ or less than by EDX. This reveals that almost all the interlayer should be ashed away. 


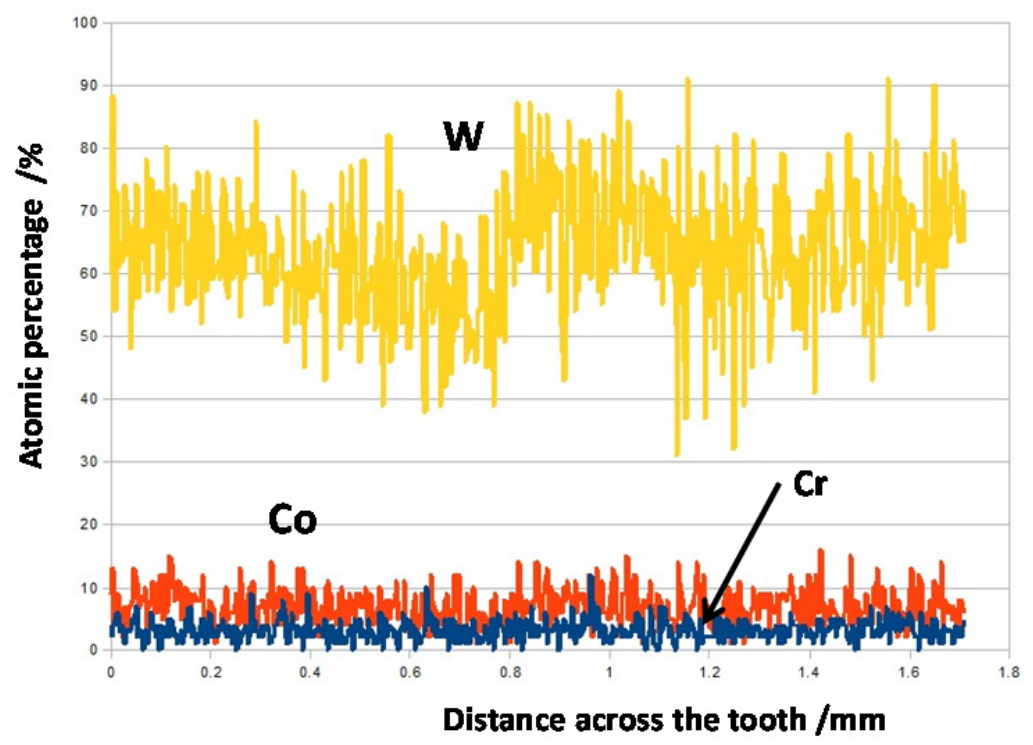

Figure 7. Distribution of chemical components on the ashed tool surface around the first tooth analyzed by EDX

\subsection{Dry End-Milling Test of DLC-Recoated WC (Co) Tools up to $200 \mathrm{~m}$ in Distance}

After complete ashing of used DLC coating as shown in Figure 5a), the original end-milling substrate was ground and polished before DLC-recoating. The same ion-plating system was also used for this recoating process. The DLC-recoated end-milling tool was fixed into a holder in DMU50 with BT40 spindle. Dry machining test was continued under the milling conditions in Table 2. Figure 8 depicts the optical microscopic images of the first tooth in the DLC-recoated end-milling tool after dry machining for $200 \mathrm{~m}$. No chipping or tiny defects are seen both at the tooth edge and on the skew tooth surface. This proves that the quality of original tool material and its tooth configuration are preserved even by DLC-ashing and by DLC-recoating, respectively

\subsection{Dry End-Milling Test of DLC-Recoated WC (Co) Tools up to $240 \mathrm{~cm}^{3}$ in Removed Volume}

Different from the milling of steels, a bulk part is often directly produced by machining the aluminum alloy block. Hence, dry machinability in three dimensional milling has to be evaluated by DLC-recoated tools. The objective volume of aluminum alloys to be removed was determined to be $240 \mathrm{~cm}^{3}$; the three-tooth cutting tool as shown in Figure 2c) was employed for this dry machining test.

Figure 9 shows the tooth configuration for three teeth after dry milling to remove $240 \mathrm{~cm}^{3}$. No chipping or damages are seen in each tooth surface even in the heavy machining conditions as listed in Table 3. In particular, no deterioration on the skew tooth surfaces and edges demonstrates that bulk aluminum alloy parts could be machined out in dry from material block even by using the DLC-recoated tools.

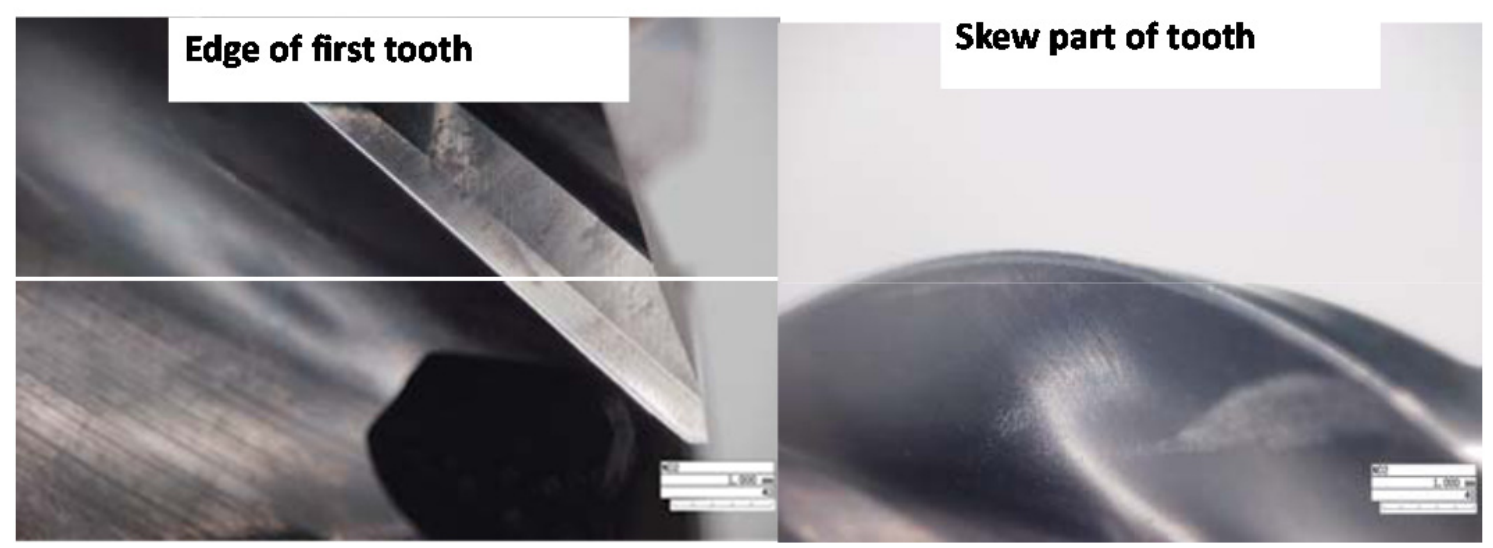

Figure 8. Tooth surfaces of DLC-recoated end-milling tools after dry cutting in $200 \mathrm{~m}$ 

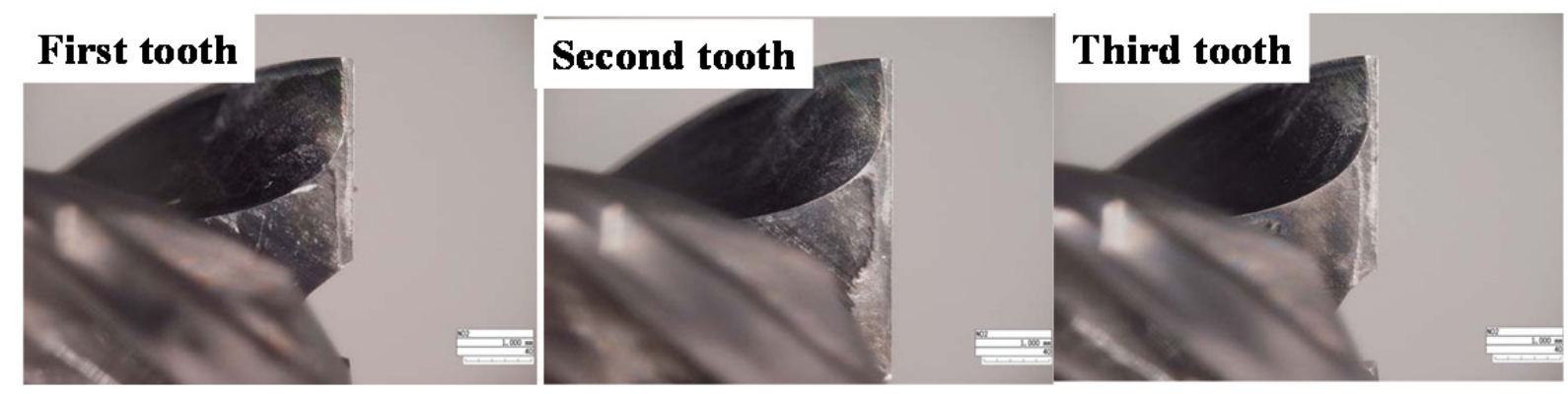

Figure 9. Tooth surfaces of DLC-recoated end-milling tools after dry machining to remove $240 \mathrm{~cm}^{3}$

\section{Discussion}

\subsection{Ashing Rate of DLC-Coated Tools}

The effective ashing rate of DLC coating from the tool substrate is determined by three processes: i.e. two ashing processes of DLC layer and metallic interlayers and a homogeneous ashing process of the whole tool surfaces. As reported in (Okimoto, Kumakiri, \& Tamagaki, 2002), the oxygen ashing system in commercial succeeded in removal of DLC coating. The hollow-cathode discharging method removed the DLC coating by the rate of 0.5 $\mu \mathrm{m} / \mathrm{H}$. In the present system, the ashing rate of bare DLC coating is $7.2 \mu \mathrm{m} / \mathrm{H}$, or, faster than the above standard approach by fourteen times. This difference comes from higher population of activated oxygen ions and radicals accompanied with high electron density.

In usual DLC-coating of tools, metallic interlayers such as chromium or tungsten are also coated onto the bare tool surfaces. As the second process, these metallic layers must be also removed in fast rate. Here the high population of oxygen ions and radicals is needed to make ashing the metallic layer. In fact, no metallic layers could be removed by the conventional oxygen plasma processing in (Okimoto, Kumakiri, \& Tamagaki, 2002). On the other hand, chromium interlayer is completely removed together with main DLC films by the present approach. This might be because metallic components $(\mathrm{M})$ could react with oxygen flux of $\mathrm{O}^{*}$ or $\mathrm{O}^{+}$by $\mathrm{M}+\mathrm{O}^{*}$ $\rightarrow \mathrm{MO}$ or $\mathrm{M}+\mathrm{O}^{+}+\mathrm{e} \rightarrow \mathrm{MO}$ and the resultant metallic monoxide (MO), be ejected from the system. More ashing time is needed for removal of metallic layers; e.g. the ashing rate for DLC-coated end-milling tools is 1.5 $\mu \mathrm{m} / \mathrm{H}$, or, around $1 / 5$ of the ashing rate for bare DLC coating.

Homogeneous ashing process is controlled by the electro-magnetic field in the chamber. When the specimen holder is located at the center of cathode table, the DLC film thickness at the root of teeth was reduced but not completely removed. On the other hand, no DLC films were left on every part of tooth surfaces in Figure 2 when the specimen holder was located on the edge of cathode table as illustrated in Figure 1b). This difference might come from the strength of electro-magnetic field to keep plasma immersion state around the specimen. Hence, a cathode design is of much importance to drive the homogeneous ashing.

\subsection{Ashing Behavior of DLC-Coated Tools}

In general, two processes work in oxygen plasma ashing of the used DLC coatings: i.e. physical bombardment process and chemical reaction process. In the former, the higher bias voltage in plasma ashing stimulates this bombardment effect but often results in the damage of tool substrate surface quality or in the deterioration of tool materials. Furthermore, ashing process turns to be inhomogeneous by the shadow effect, where the activated species attack only on the partial region of tools. In the present study, DC bias was limited at most by $-600 \mathrm{~V}$ to be free from heavy bombardment effects during the ashing process.

Among the activated species, both $\mathrm{O}^{*}$ and $\mathrm{O}^{+}$are responsible for chemical reaction to carbon in DLC by $\mathrm{C}+\mathrm{O}^{*}$ $\rightarrow \mathrm{CO}$ and $\mathrm{O}^{+}+\mathrm{e}+\mathrm{C} \rightarrow \mathrm{CO}$. Relatively higher intensity of $\mathrm{CO}$ detected in Figure $3 \mathrm{~b}$ ) proves that high ion and electron density state should be necessary to promote the above chemical reaction. Once the carbon-base coatings were under this high density plasma immersion state, it must be ashed away in fast rate. As depicted in Figure 3a), oxygen ions with higher covalent number or $\left\{\mathrm{O}^{2+}, \mathrm{O}^{3+}, \ldots\right\}$ were present together with $\mathrm{O}^{*}$ and $\mathrm{O}^{+}$in the activated plasmas. Their role in the chemical reaction might be also considered to make quantitative description on the ashing process.

\subsection{Characteristics for Green Manufacturing}

The present recycling of end-milling tools provides a solution to requirement for green manufacturing by dry 
machining of aluminum alloy parts. First, a large amount of lubricating oils is saved by this technology to be in the minimum level. After the report on the impact of dry forming in (Aizawa \& Morita, 2012), the production cost might be reduced in 30\% besides the post-treatment cost of used lubricating oils. In second, the originally designed tool substrate is repeatedly reused by complete ashing and recoating the DLC coating. Although light grinding and polishing processes might be necessary to adjust the tooth configuration, the tooling cost must be much reduced without deterioration of accuracy in machining. More resource for tool substrate materials is further saved by this reuse of tools; after (Allwood \& Cullen, 2012), this resource material saving becomes a key as a sustainable manufacturing. In third, the chemical cleansing process for machined products is never necessary to ship the machined parts and components after mechanical polishing. This reduction of environmental burdens is also essential in the sustainable manufacturing.

\section{Conclusion}

High density oxygen ashing system was developed and applied to make removal of DLC coating from DLC-coated milling tools for dry cutting of aluminum alloys. Perfect ashing of DLC-coating as well as removal of metallic interlayers with high ashing rate is preferable to recycling the used tool substrate. The DLC-recoated tools after the present ashing process have the same machinability as the virgin DLC-coated tools. This demonstrates that the tool substrates are reused only by post-grinding and recoating after the present ashing process.

Plasma immersion state might be necessary to preserve the fast-rate ashing process even for DLC-coated tools with complexity in geometry. In particular, high electron and ion density distribution is required for complete ashing of the carbon base coatings such as DLC or CVD diamond coatings to reuse the WC (Co) tools. In the latter case, the present recycling method is indispensable to repeatedly reuse the $\mathrm{WC}(\mathrm{Co})$ tool substrate materials toward the dry machining and milling of CFRP (Carbon Fiber Reinforced Plastics) or CFRTP (Carbon Fiber Reinforced Thermoplastic Plastics) plates and components for aircraft and automobiles. In addition, a massive ashing of used tool stock in the batch mode requires for fine control of oxygen atom and ion flux even in the oxygen plasma immersion state.

\section{Acknowledgements}

The authors would like to express their gratitude to Dr. H. Matsuoka (Matsuoka Technology Research, Co. Ltd.) for his advice in experiments. This study was financially supported in part by MEXT-project with the contract of $\# 411419$, and, by SIT-project with the contract of \#411501, respectively.

\section{References}

Aizawa, T. (2011). Micro-patterning onto diamond like carbon coating via RF-DC oxygen plasma etching. Proc. 5th SEATUC Conference (Vietnam, Hanoi), 425-428.

Aizawa, T., \& Fukuda, T. (2012). Micro-patterning onto carbon-based coatings via oxygen plasma etching. Res. Rep. Shibaura Institute of Technology, 56(2), 47-56.

Aizawa, T., \& Fukuda, T. (2013). Oxygen plasma etching of diamond-like carbon coated mold-die for $\begin{array}{lllll}\text { micro-texturing. Surface } \quad \text { and } & \text { Coatings }\end{array}$ http://dx.doi.org/10.1016/j.surfcoat.2012.07.095

Aizawa, T., \& Morita, H. (2012). Semi-dry transfer stamping by nano-laminated DLC coated dies and tools. Res. Rep. Shibaura Institute of Technology, 56(1), 27-36.

Aizawa, T., \& Sugita, Y. (2011). High density plasma technology for etching and ashing of carbon materials. Res. Rep. Shibaura Institute of Technology, 55(1), 13-22.

Aizawa, T., Masaki, E., \& Sugita, Y. (2013). Oxygen plasma ashing of used DLC coating for reuse of milling and cutting tools. Proc. 10th International Conference on Materials Processing Technology (BKK, Thai), 15-20.

Aizawa, T., Masaki, E., \& Sugita, Y. (2014). Complete ashing of used DLC coating for reuse of the end-milling tools. Manufacturing Letters, 2(1) 1-3. http://dx.doi.org/10.1016/j.mfglet.2013.10.006

Aizawa, T., Mizushima, K., Redationo, T. N., \& Yang, M. (2013). Micro-imprinting onto DLC and CNT coatings via high density oxygen plasma etching. Proc. 8th ICOMM Conference (Canada, Victoria), 459-466.

Allwood, J. M., \& Cullen, J. M. (2012). Sustainable materials. UIT.

Cole, G., Glove, A., Jeryan, R., \& Davies, G. (1997). Steel World, 2, 75-83.

Cuesta, A., Mart'inez-Alonso, A., \& Tasco'n, J. M. D. (2001). Carbon reactivity in an oxygen plasma: a comparison with reactivity in molecular oxygen. Carbon, 39, 1135-1146. 
http://dx.doi.org/10.1016/S0008-6223(00)00235-9

Cvelbar, U., Krstulovi, N., Miloševi, S., \& Mozeti, M. (2007). Inductively coupled RF oxygen plasma characterization by optical emission spectroscopy. Vacuum, 82(2), 224-227. http://dx.doi.org/10.1016/j.vacuum.2007.07.016

Gangopadhyay, S., Acharya, R., Chattopadhyay, A. K., \& Sargade, V. G. (2010). Effect of cutting speed and surface chemistry of cutting tools on the formation of bul or bue and surface quality of the generated surface in dry turning of AA6005 aluminum alloy. Machining Science Technology, 14(2), 208-223. http://dx.doi.org/10.1080/10910344.2010.500961

Japan Coating Center. (2014). Retrieved 11th January, 2014 from http://www.jcc-coating.co.jp

Jones, B. J. (2012). Substrate and material transfer effects on the surface chemistry and texture of diamond-like carbon deposited by plasma-enhanced chemical vapor deposition. Surface and Interface Analysis, 26, 431-436. http://dx.doi.org/10.1002/sia.4871

Okimoto, T., Kumakiri, T., \& Tamagaki, H. (2002). Application of hollow cathode plasmas to $\mathrm{SiO}_{\mathrm{x}}$ coating. Future: Advance thin film technology in Research Report of KOBELCO 52(2), 2002, 13-18.

Saloum, S., Naddaf, M., \& Alkhaled, B. (2010) Active species characterization in RF remote oxygen plasma using actinometry OES and electrical probes. Vacuum, 85, 439-442. http://dx.doi.org/10.1016/j.vacuum.2010.08.007

Samsong. $\quad$ (2013). $\quad$ Retrieved $\quad$ 19th $\quad$ April, 2013 from http://au.ibtimes.com/articles/457503/20130416/iphone-5s-samsung-galaxy-s4-note-3.thm

Suenaga, R., Yunata, E. E., \& Aizawa, T. (2013). Quantitative plasma diagnosis on high density RF-DC plasmas for surface processing. Proc. 7th SEATUC Conference. OS-6-19 (Bandung), 1-4.

Zolgharni, M., Jones, B. J., Bulpett, R., Anson, A. W., \& Franks, J. (2008). Energy efficiency improvements in dry drilling with optimized diamond-like carbon coatings. Diamond and Related Materials, 17(7-10), 1733-1737. http://dx.doi.org/10.1016/j.diamond.2007.11.012

\section{Copyrights}

Copyright for this article is retained by the author(s), with first publication rights granted to the journal.

This is an open-access article distributed under the terms and conditions of the Creative Commons Attribution license (http://creativecommons.org/licenses/by/3.0/). 